The Politics of

Social Media Manipulation 



\title{
The Politics of Social Media Manipulation
}

\author{
Edited by \\ Richard Rogers \\ and Sabine Niederer
}


Cover design: Coördesign, Leiden

Typesetting: Crius Group, Hulshout
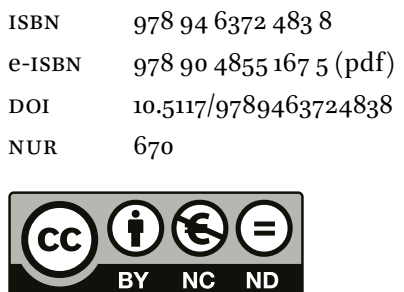

Creative Commons License CC BY NC ND (http://creativecommons.org/licenses/by-nc-nd/3.o)

@ All authors / Amsterdam University Press B.V., Amsterdam 2020

Some rights reserved. Without limiting the rights under copyright reserved above, any part of this book may be reproduced, stored in or introduced into a retrieval system, or transmitted, in any form or by any means (electronic, mechanical, photocopying, recording or otherwise). 